\title{
AVALIAÇÃO DA QUALIDADE DE POLPA DE GOIABA 'PALUMA' ARMAZENADA $\mathrm{A}-\mathbf{2 0} \mathbf{C}^{\circ}$
}

\author{
MARIA AMALIA BRUNINI², ANTONIO LUÍS DE OLIVEIRA², DANIEL BARBOSA VARANDA4
}

\begin{abstract}
RESUMO - Neste estudo, goiabas da cultivar 'Paluma' foram cortadas em duas partes e submetidas a diferentes processos de conservação antes do armazenamento a $-20^{\circ} \mathrm{C}$. No primeiro processo a polpa dura foi triturada, acondicionada em sacos de polietileno, com espessura de $40 \mu \mathrm{m}$, congelada e armazenada $\mathrm{a}-20^{\circ} \mathrm{C}^{\circ}$, e no segundo processo a polpa dura foi cortada ao meio, branqueada em água quente a $98^{\circ} \mathrm{C}$ por quatro minutos, seca e acondicionada em sacos de polietileno, com espessura de $40 \mu \mathrm{m}$, congelada e armazenada a $-20^{\circ} \mathrm{C}$. A qualidade da polpa foi avaliada através do $\mathrm{pH}$, teor de ácido ascórbico, sólidos solúveis totais, acidez total titulável, aparência, textura e coloração. As duas formas de conservação mostraram-se adequadas para preservação da polpa com boa aparência até 18 semanas. Houve redução no conteúdo de ácido ascórbico, principalmente na polpa triturada. A textura e o sabor da polpa foram afetados pelo tempo de armazenamento. Os dois procedimentos, como técnicas de preservação de goiabas pelas indústrias de alimentos, podem ser usados durante o período de safra, sendo uma boa alternativa para evitar perdas pós-colheita. Termos de indexação: Psidium guajava, armazenamento, qualidade e vida de prateleira.
\end{abstract}

\section{QUALITY EVALUATION OF 'PALUMA' GUAVA PULP STORED AT $-20^{\circ} \mathrm{C}$}

ABSTRACT - In this study, guava fruits cv. Paluma were cut in two parts and submitted to different processing condition before storage at $-20^{\circ} \mathrm{C}$. In the first process the fruit pulp were tritured and conditioned in polyethylene bags with $40 \mu \mathrm{m}$ of thickness, frozen and stored at $-20^{\circ} \mathrm{C}$ in refrigerated chamber; and in the second process the slices of the pulp fruit were treated with hot-water at $98^{\circ} \mathrm{C}$ by four minutes, dried and conditioned in polyethylene bags with $40 \mu \mathrm{m}$ of thickness, frozen and stored at $-20^{\circ} \mathrm{C}$. The pulp quality was avaliable throught the $\mathrm{pH}$, ascorbic acid content, total soluble solids, titrable acidity, general appearance, firmness and color. The two process used were able to preserve the pulp with good aspect until 18 week. The content of ascorbic acid decreased, principally, in the tritured pulp fruits. The texture and flavor was affected by the storage time. The two procedures studied as a technique for the preservation of pulp of guava fruits by food industry can be used during harvest time being an alternative to avoid postharvest loses.

Index terms: Psidium guajava, storage, quality and shelf life.

\section{INTRODUÇÃO}

A goiaba (Psidium guajava, L) é originária da região tropical das Américas, foi disseminada para as diferentes regiões do mundo (Lemos et al, 1995) e constitui-se em uma das mais importantes matérias prima para as indústrias de sucos, polpas e néctares. Tem grande aceitação no mercado, sendo considerada uma das melhores fontes de vitamina $\mathrm{C}$, apresentando conteúdo de ácido ascórbico variando de 55 a $1.044 \mathrm{mg}$ de ácido ascórbico por $100 \mathrm{~g}$ de polpa, de acordo com a cultivar, local e manejo (Rathore, 1976; Menzel, 1985; Carvalho, 1994).

A polpa de fruta é o produto obtido da parte comestível dos frutos, após trituração e/ou despolpamento e preservado por processos físicos como pasteurização e congelamento (Brunini et al, 2002). O processamento de goiaba para obtenção de polpa é uma atividade agroindustrial importante na medida em que agrega valor econômico à fruta, evitando desperdícios e minimizando as perdas que podem ocorrer durante a comercialização do produto 'in natura'(Furtado et al, 2000), além de permitir aumentar sua vida útil com manutenção da qualidade. Geralmente, as polpas são comercializadas em embalagens flexíveis ( sacos plásticos de polietileno) ou tetrapak, dado a facilidade de manuseio e a proteção contra oxidação. As embalagens, além de evitar as alterações das características sensoriais do produto, devem satisfazer as necessidades demarketing e custo. Como a goiaba é rica em vitamina $\mathrm{C}$, o tipo de embalagem utilizada no acondicionamento tem influência na vida de prateleira, pois esta vitamina é hidrossolúvel, apresenta pouca estabilidade e está sujeita à degradação pelo oxigênio, luz, $\mathrm{pH}$, açúcares e aminoácidos livres (Cid et al, 1991; Oliveira et al, 1996).

Considerando que a maioria da produção de frutos de goiabeira concentra-se no período de janeiro a fevereiro e a importância do aproveitamento dos excedentes de produção, tem-se que o processamento da goiaba em derivados, como polpas íntegras e trituradas, merece atenção dada a utilização dos mesmos como matéria prima de indústrias secundárias ou para consumo direto.

Neste trabalho objetivou-se estudar a qualidade e vida de prateleira da goiaba 'Paluma', processada na forma de polpa triturada e polpa íntegra congelada durante o armazenamento a $-20^{\circ} \mathrm{C}$.

\section{MATERIAL E MÉTODOS}

Utilizou-se goiabas da cultivar 'Paluma' (polpa vermelha) provenientes de pomar comercial situado em Pedregulho-SP. Os frutos foram colhidos maduros, no período da manhã, rapidamente transportados para o Laboratório de Fruticultura da Faculdade de Agronomia "Dr. Francisco Maeda"/FEI, Ituverava-SP, onde depois de lavados com solução de hipoclorito de sódio a $250 \mu \mathrm{g} \mathrm{mL} \mathrm{m}^{-1}$ foram selecionados, descartando-se aqueles com lesões mecânicas.

Os frutos do primeiro lote foram cortados ao meio e, após a retirada do miolo mole, a polpa foi triturada e acondicionada em sacos plásticos de polietileno de espessura $0,040 \mu \mathrm{m}$, na quantidade aproximada de 100 a $150 \mathrm{~g}$. As embalagens foram fechadas hermeticamente com máquina seladora. A polpa foi congelada e armazenada a $-20^{\circ} \mathrm{C}$ em câmara de congelamento.

Os frutos do segundo lote foram cortados ao meio e, após a retirada do miolo mole, a polpa dura foi branqueada em água quente a $98^{\circ} \mathrm{C}$ por 4 minutos, resfriada, seca ao ar, acondicionada em sacos plásticos de polietileno de $0,040 \mathrm{~mm}$ de espessura, na quantidade aproximada de $500 \mathrm{~g}$. A embalagem foi fechada hermeticamente, congelada e armazenada a $-20^{\circ} \mathrm{C}$ em câmara de congelamento. A qualidade da polpa foi avaliada, quinzenalmente, quanto ao teor de sólidos solúveis totais, acidez total titulável, $\mathrm{pH}$, teor de ácido ascórbico, aparência,

${ }^{1}$ (Trabalho 177/2002). Recebido: 27/12/2002. Aceito para publicação: 24/10/2003.

${ }^{2}$ Professora adjunto aposentada da Faculdade de Ciências Agrárias e Veterinárias de Jaboticabal/UNESP e Professora Pesquisadora da Faculdade "Dr. Francisco Maeda"/FEI. Rodovia Jerônimo Nunes Macedo, Km 01, CEP=14500-000, Ituverava-SP. Telefone: 0 XX 16- 3729 3199. E-mail: amaliabrunini@netsite.com.br. ${ }^{3}$ Professor Doutor da Faculdade "Dr. Francisco Maeda"/FEI. Rodovia Jerônimo Nunes Macedo, Km 01, CEP=14500-000, Ituverava-SP. Telefone: 0 XX 16- 3729 3199. E-mail: toca@netsite.com.br.

${ }^{4}$ Acadêmico do Curso de Agronomia da Faculdade "Dr. Francisco Maeda"/FEI. Rodovia Jerônimo Nunes Macedo, Km 01, CEP=14500-000, Ituverava-SP Telefone: 0 XX 3729 3199. E-mail:danivaranda@hotmail.com.br. 
sabor e coloração. A polpa íntegra do segundo lote foi, também, avaliada quanto à textura, através de degustação, por quinze provadores treinados, utilizando-se de uma escala de notas, onde: $1=$ dura, $2=$ firme, $3=$ mole, $4=$ muito mole. O sabor da polpa do primeiro e segundo lote foi avaliado, também, por degustação, por quinze provadores treinados, utilizando-se uma escala de notas, onde: $1=$ ácido, $2=$ típico, $3=$ amargo. A aparência e coloração foram avaliadas visualmente, através de uma escala de notas, onde $1=$ boa, $2=$ razoável, $3=$ ruim, para a aparência, e $1=$ coloração típica da polpa do fruto, $2=$ polpa com regiões opacas e/ ou amarelas e $3=$ polpa completamente opaca e/ou amarela, para a coloração.

Determinou-se, de acordo com as normas do Instituto Adolfo Lutz (1985), a acidez total titulável, o conteúdo de sólidos solúveis totais ( $\left.{ }^{\circ} \mathrm{Brix}\right)$ e os teores de vitamina $\mathrm{C} . \mathrm{O}$ pH foi determinado segundo normas da AOAC (1980).

Os dados foram submetidos à análise de variância e as médias comparadas com o valor inicial através do teste de Tuckey, ao nível de $5 \%$ de probabilidade (Banzatto \& Kronka, 1995).

\section{RESULTADOS E DISCUSSÃO}

A polpa de goiaba triturada, congelada e armazenada a $-20^{\circ} \mathrm{C}$ manteve aparência e coloração em condições de comercialização por até 18 semanas, tempo em que o sabor (nota 2) e a coloração (nota 1) permaneceram típica (Figura 1).

Pelos dados apresentados na Tabela 1 pode-se verificar que o conteúdo de vitamina $\mathrm{C}$ (expresso em $\mathrm{mg}$ de ácido ascórbico por $100 \mathrm{~g}$ de polpa) diminuiu de 67,86 para 10,07, em 18 semanas, concordando com a afirmação de Cid et al (1991) e Oliveira et al (1996). Os valores aqui encontrados diferem dos citados para a goiaba vermelha 'in natura' por Franco (1997) que é em média de 45,6 a 80,2mg $100 \mathrm{~g}^{-1}$.

Os valores de acidez total titulável e do $\mathrm{pH}$ (Tabela 1) mostram que a polpa conservou sua acidez durante o armazenamento. Os valores de $\mathrm{pH}$ variaram de 3,15 a 4,03 e estão dentro do limite citados por Yusof (1990) para diversas variedades de goiaba. Os dados apresentados na Tabela 1 mostram que a acidez titulável variou, durante o período de armazenamento, de 0,406 a $0,51 \mathrm{~g}$ de ácido cítrico por $100 \mathrm{~g}$, valores estes diferentes dos citados por Morais (1998), que é de 0,399 a $0,217 \mathrm{~g}$ de ácido cítrico por $100 \mathrm{~g}$.

Os teores de sólidos solúveis totais (Tabela 1) variaram de 9,09 a $7,17^{\circ}$ Brix, e esta oscilação foi mais significativa em função do tempo de armazenamento, provavelmente em função do teor de umidade do ambiente que pode ter ocasionado perda de umidade pela polpa, através do filme plástico. Os valores aqui encontrados estão dentro do intervalo encontrado para frutos 'in natura', da mesma cultivar, por Paro (1996).

Os resultados apresentados na Figura 2 mostram que as polpas não trituradas e em pedaços, congeladas, de goiaba 'Paluma' mantiveram-se, também, com boa qualidade por até 18 semanas, comprovado pela manutenção de coloração, sabor e textura, pois a partir desta data começaram a apresentar textura mole, coloração com manchas opacas e amarelas e sabor amargo. Comparando-se estes resultados com os obtidos para a polpa triturada, verifica-se que a vida de prateleira foi semelhante, apesar da polpa íntegra em pedaço ter retido maior teor de vitamina $\mathrm{C}$ e sólidos solúveis totais (Tabela 2).

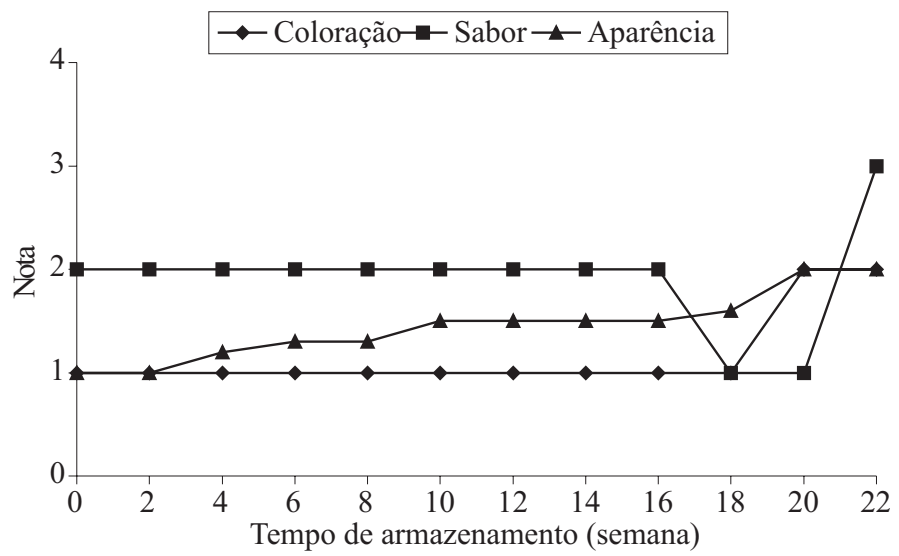

FIGURA 1 - Evolução da coloração, sabor e aparência em polpa triturada e congelada de goiaba 'Paluma', durante o armazenamento a $-20^{\circ} \mathrm{C}$.

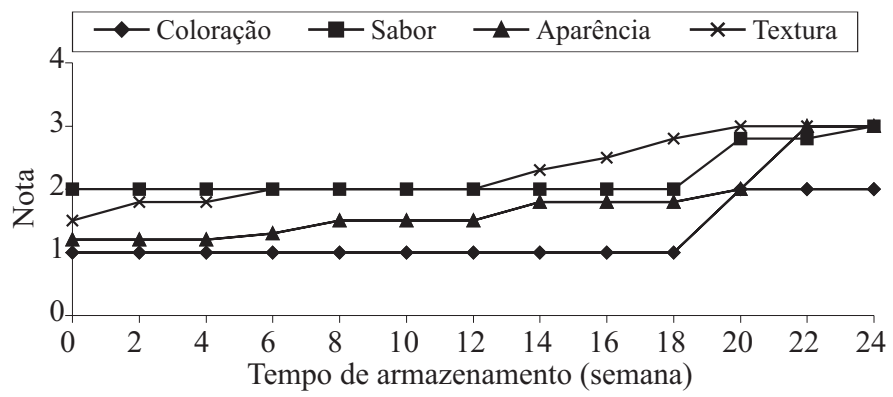

FIGURA 2 -Evolução da coloração, sabor, aparência e textura em polpa dura cortada ao meio e congelada de goiaba 'Paluma', durante $\mathrm{o}$ armazenamento $\mathrm{a}-20^{\circ} \mathrm{C}$.

TABELA 1 - Acidez total titulável, sólidos solúveis totais, pH e vitamina $\mathrm{C}$ em polpa triturada e congelada de polpa de goiaba 'Paluma' durante armazenamento a $-20^{\circ} \mathrm{C}$. Ituverava-SP 2001. (média de 5 repetições)

\begin{tabular}{|c|c|c|c|c|}
\hline $\begin{array}{l}\text { Tempo de armazenamento } \\
\text { (semana) }\end{array}$ & $\begin{array}{l}\text { Acidez (g de ácido cítrico } \\
\text { por } 100 \mathrm{~g} \text { de polpa) }\end{array}$ & $\begin{array}{l}\text { Sólidos solúveis totais } \\
\text { ( }{ }^{\circ} \text { Brix) }\end{array}$ & $\mathrm{pH}$ & $\begin{array}{l}\text { Vitamina C (mg de ácido } \\
\text { ascórbico } 100 \mathrm{~g} \text { de polpa })\end{array}$ \\
\hline Polpa fresca & $0,408 \mathrm{ij}$ & $9,09 \mathrm{a}$ & $3,86 \mathrm{~b}$ & $67,86 \mathrm{a}$ \\
\hline 0 & $0,421 \mathrm{f}$ & $9,01 \mathrm{~b}$ & $3,87 \mathrm{~b}$ & $56,17 \mathrm{~b}$ \\
\hline 2 & $0,406 \mathrm{j}$ & $8,99 b$ & $3,79 c$ & $40,84 d$ \\
\hline 4 & $0,515 \mathrm{a}$ & $8,36 \mathrm{f}$ & $3,86 \mathrm{~b}$ & $41,36 \mathrm{c}$ \\
\hline 6 & $0,456 \mathrm{c}$ & $8,49 \mathrm{~d}$ & $3,81 \mathrm{c}$ & $32,73 \mathrm{e}$ \\
\hline 8 & $0,405 \mathrm{j}$ & $8,45 \mathrm{e}$ & $3,63 \mathrm{f}$ & $29,16 \mathrm{f}$ \\
\hline 10 & $0,411 \mathrm{hi}$ & $8,77 \mathrm{c}$ & $4,03 \mathrm{a}$ & $28,25 \mathrm{~g}$ \\
\hline 12 & $0,499 b$ & $8,39 \mathrm{f}$ & $3,89 \mathrm{~b}$ & $25,46 \mathrm{~h}$ \\
\hline 14 & $0,430 \mathrm{e}$ & $8,24 \mathrm{~g}$ & $3,70 \mathrm{de}$ & $22,18 \mathrm{i}$ \\
\hline 16 & $0,450 \mathrm{~d}$ & $7,99 \mathrm{~h}$ & $3,69 \mathrm{e}$ & $15,25 \mathrm{j}$ \\
\hline 18 & $0,416 \mathrm{~g}$ & $8,36 \mathrm{f}$ & $3,86 \mathrm{~b}$ & $10,07 \mathrm{k}$ \\
\hline 20 & $0,410 \mathrm{hi}$ & $8,49 \mathrm{~d}$ & $3,73 \mathrm{~d}$ & 9,631 \\
\hline 22 & $0,413 \mathrm{gh}$ & $7,17 \mathrm{i}$ & $3,15 \mathrm{~g}$ & $5,41 \mathrm{~m}$ \\
\hline Média & 0,43 & 8,44 & 3,75 & 29,56 \\
\hline c.v. $(\%)$ & 0,28 & 0,13 & 0,32 & 0,04 \\
\hline $\mathrm{d} \mathrm{m} \mathrm{s}$ & 0,00 & 0,03 & 0,03 & 0,03 \\
\hline
\end{tabular}

* Médias seguidas de letras iguais nas colunas não diferem entre si pelo teste de Tukey a $5 \%$ de probabilidade 
TABELA2 - Acidez total titulável, sólidos solúveis totais, $\mathrm{pH}$ e vitamina $\mathrm{C}$ em polpa dura cortada ao meio íntegra e congelada de goiaba 'Paluma' durante armazenamento a $-20^{\circ} \mathrm{C}$. Ituverava-SP, 2001. (média de 5 repetições)

\begin{tabular}{|c|c|c|c|c|}
\hline $\begin{array}{l}\text { Tempo de armazenamento } \\
\text { (semana) }\end{array}$ & $\begin{array}{c}\text { Acidez (g de ácido cítrico } \\
\left.\text { por } 100 \mathrm{~g}_{\text {de }} \text { polpa }^{-1}\right)\end{array}$ & $\begin{array}{c}\text { Sólidos solúveis totais } \\
\text { ( }{ }^{\circ} \text { Brix) }\end{array}$ & $\mathrm{pH}$ & $\begin{array}{l}\text { Vitamina C (mg de ácido } \\
\left.\text { ascórbico } .100 \mathrm{~g} \text { de polpa }{ }^{-1}\right)\end{array}$ \\
\hline Polpa fresca & $0,408 \mathrm{bc}$ & $9,09 \mathrm{a}$ & $3,86 \mathrm{bc}$ & $67,86 \mathrm{a}$ \\
\hline 0 & $0,407 \mathrm{bc}$ & $9,09 \mathrm{a}$ & $3,93 \mathrm{a}$ & $59,34 b$ \\
\hline 2 & $0,409 b$ & $9,03 \mathrm{~b}$ & 3,79 ef & $50,45 \mathrm{c}$ \\
\hline 4 & $0,403 d$ & $8,90 \mathrm{c}$ & 3,81 de & $42,49 d$ \\
\hline 6 & $0,379 \mathrm{~g}$ & $8,09 \mathrm{i}$ & $3,84 \mathrm{~cd}$ & $40,64 \mathrm{e}$ \\
\hline 8 & $0,414 \mathrm{a}$ & $8,39 \mathrm{~g}$ & $3,71 \mathrm{~h}$ & $31,98 \mathrm{f}$ \\
\hline 10 & $0,405 \mathrm{~cd}$ & $8,77 \mathrm{~d}$ & $3,89 b$ & $31,95 \mathrm{f}$ \\
\hline 12 & $0,378 \mathrm{~g}$ & $9,03 \mathrm{~b}$ & 3,81 de & $26,87 \mathrm{~h}$ \\
\hline 14 & $0,388 \mathrm{f}$ & $8,37 \mathrm{gh}$ & $3,78 \mathrm{ef}$ & $26,97 \mathrm{~g}$ \\
\hline 16 & $0,397 \mathrm{e}$ & $8,52 \mathrm{f}$ & $3,80 \mathrm{e}$ & $22,48 \mathrm{i}$ \\
\hline 18 & $0,368 \mathrm{~h}$ & $8,92 \mathrm{c}$ & 3,81de & $17,44 \mathrm{j}$ \\
\hline 20 & $0,379 \mathrm{~g}$ & $8,89 \mathrm{c}$ & $3,61 \mathrm{i}$ & $16,57 \mathrm{k}$ \\
\hline 22 & $0,399 \mathrm{e}$ & $8,34 \mathrm{~h}$ & $3,73 \mathrm{gh}$ & 13,261 \\
\hline 24 & $0,362 \mathrm{i}$ & $8,59 \mathrm{e}$ & $3,76 \mathrm{fg}$ & $10,18 \mathrm{~m}$ \\
\hline Média & 0,39 & 8,71 & 3,79 & 37,74 \\
\hline c.v $(\%)$ & 0,28 & 0,13 & 0,31 & 0,04 \\
\hline $\mathrm{d} \mathrm{m} \mathrm{s}$ & 0,00 & 0,03 & 0,03 & 0,03 \\
\hline
\end{tabular}

${ }^{*}$ Médias seguidas de letras iguais nas colunas não diferem entre si pelo teste de Tukey a $5 \%$ de probabilidade.

Os teores de vitamina $\mathrm{C}$ nas polpas íntegras, congeladas e armazenadas a $-20^{\circ} \mathrm{C}$ decresceu dos iniciais $67,86 \mathrm{mg}$ de ácido ascórbico por $100 \mathrm{~g}$ de polpa, na polpa fresca, para $17,44 \mathrm{mg}$ de ácido ascórbico por $100 \mathrm{~g}$ de polpa após 18 semanas e diferem dos valores citados por Franco (1997) para goiabas vermelhas. Pode-se observar que o teor de vitamina $\mathrm{C}$, tanto na polpa congelada na forma triturada como na não triturada, foi afetada pelo tipo de preparo e também pelo tempo de armazenamento, pois com a manipulação da goiaba ocorreu perda deste nutriente, da ordem de $17,23 \%$ e de $12,56 \%$, respectivamente, durante a trituração e o corte da polpa (Tabela 1 e 2).

A acidez titulável nas polpas duras cortadas ao meio, congeladas e armazenadas a $-20^{\circ} \mathrm{C}$ (Tabela 2) mostram que a fruta conservou sua acidez e que as diferenças encontradas podem ser atribuídas às diferenças entre amostras. Os valores encontrados são maiores que os citados para a mesma cultivar 'in natura' por Morais et al (1997), indicando a possibilidade de utilização deste material sem conservante.

Os teores de sólidos solúveis totais apresentaram pequena diminuição ao longo do período de armazenamento, de 9,09 ${ }^{\circ}$ Brix, na polpa fresca, para 8,92 após 18 semanas de armazenamento. Os valores aqui encontrados estão dentro do intervalo encontrado para a fruta 'in natura' da mesma cultivar por Paro (1996).

\section{CONCLUSÃO}

A polpa de goiaba na forma triturada e em pedaços íntegros pode ser armazenada por até 18 semanas a $-20^{\circ} \mathrm{C}$; os teores de vitamina $\mathrm{C}$ diminuíram drasticamente com o tempo de armazenamento principalmente quando armazenado na forma triturada; a textura da polpa íntegra congelada foi alterada após 18 semanas de armazenamento.

\section{AGRADECIMENTOS}

Os autores agradecem a Fundação Educacional de ItuveravaFEI pelo apoio na realização deste trabalho.

\section{REFERÊNCIAS BIBLIOGRÁFICAS}

AOAC. Of ficial methods of analysis of the Association of Official Analytical Chemists. 13 ed. Washington: AOAC., 1980, 1018p.

BANZATTO, D. A., KRONKA, S. N. de. Experimentação agrícola. 3 ed. Jaboticabal: FUNEP, 1995. 247p.
BRUNINI, M.A., DURIGAN, J.F., OLIVEIRA, A.L. Avaliações das alterações em polpa de manga 'Tommy-Atkins' congelada. Revista Brasileira de Fruticultura, Jaboticabal, 2002. (no prelo)

CARVALHO, V.D. Qualidade e conservação pós-colheita de goiabas. Informe Agropecuário, Belo Horizonte-MG v.17, n.179, p.48-54, 1994.

CID, C., ASTICISARARAN, I., YBELLU, J. Modificaciones em el contenido de vitamina $\mathrm{C}$ em zumos naturales desde su elaboración hasta su posible consumo. Alimentaria, Madrid, v.28, p.41-43, 1991.

FRANCO, G. Tabela de composição química dos alimentos. 9. ed. São Paulo: Atheneu Editora, 1997.307p.

FURTADO, A.A. L; CABRAL, L. M. C., ROSA, M. de F., MODESTA, R.C.D., PONTES, S.M. Avaliação microbiológica e sensorial da polpa de goiaba tratada termicamente. Revista Brasileira de Fruticultura, Jaboticabal-SP, v.22, n.especial, p.91-95, 2000.

INSTITUTOADOLFO LUTZ. Normas analíticas do Instituto Adolfo Lutz: métodos químicos e físicos para análise de alimentos. 4.ed. São Paulo: Editora do IAL 1985. v.1,371p.

LEMOS, G.C. da S.; OLIVEIRA JUNIOR, J.C. de.; COLLIER, L.S.; CARVALHO, A.J.C. de., MANICA, I. Goiaba: amadurecimento, colheita, classificação, embalagem, transporte e armazenamento. Cadernos de Horticultura da UFRS, Porto Alegre-RS, v. 3, n.4, p.18, 1995.

MENZEL, C.M. Guava: an exotic fruit with potencial in Quessland. Quessland Agricultural Journal, Brisbane, v.111, n.2, p.93-98, 1985.

MORAIS, S.P.; KANESIRO, M.A.B.; DURIGAN, J.F.; TOSTES, D.R.D. Avaliação de polpa de goiaba congelada. In: SIMPÓSIO BRASILEIRO SOBRE A CULTURA DA GOIABEIRA, 1., 1997, Jaboticabal-SP. Resumos... Jaboticabal: FUNEP/FCAVJ, 1997. p 7.

OLIVEIRA, P.B. et al. Estudo da estabilidade do néctar de acerola. Ciência e Tecnologia deAlimentos, Campinas, v.16, n.3, p.228-232, 1996.

PARO, R.M. Conservação pós-colheita de goiabas (Psidium guajava L.) 'Paluma' empregando-se embalagem plástica e revestimento com cera, em associação com armazenamento refrigerado. 1996. 137f. Monografia (Trabalho de Graduação em Agronomia)Faculdade de Ciências Agrárias e Veterinárias, Universidade Estadual Paulista, Jaboticabal, 1996.

RATHORE, D.S. Effect of season on the growth and chemical composition of guava (Psidium guajava L.) fruits. The Journal of Horticultural Science, Ashford Kent, v.51, n.1, p.41-47, 1976.

YUSOF, S. Physico-chemical characteristics of same guava varieties in malaysia. Acta Horticulture, Netherlands, n.269, p.301-305, 1990. 